\title{
INCIDÊNCIA DE CASOS DE INFECÇÕES SEXUALMENTE TRANSMISSÍVEIS NO SUL DO ESTADO DO TOCANTINS, DURANTE OS ANOS DE 2013 A 2017
}

\section{INCIDENCE OF CASES OF SEXUALLY TRANSMITTED INFECTIONS IN THE SOUTH OF THE STATE OF TOCANTINS, DURING THE YEARS OF 2013 TO 2017}

Claudia Christina Ribeiro Guimarães Neri', Tatianne Oliveira de Sousa ${ }^{2}$, Wanessa Dourado da Silva ${ }^{3}$, Jairo Azevedo Junior ${ }^{4}$, Mira Célia Benvenuto ${ }^{5}$

\section{RESUMO}

Introdução: As Infecções Sexualmente Transmissíveis (IST) atingem grande parte da população, e algumas dessas IST são de notificação compulsória, o que contribui para um controle e diminuição destes índices. Objetivo: $O$ intuito desse estudo foi avaliar a incidência de casos de IST em indivíduos de Gurupi - TO entre os anos de 2013 a 2017. Material e métodos: A coleta de dados foi realizada no banco de dados da Vigilância Epidemiológica da Secretaria Municipal de Saúde. A incidência entre os anos foi comparada por meio do teste Qui-quadrado, ao nível de significância de $5 \%$, com o auxílio do pacote "chisq.test" do software R Development Core Team, elaborando então gráficos explicativos. Resultados: $\mathrm{Na}$ avaliação da série histórica, verificou-se que entre os anos de 2013 a 2017, segundo a Secretaria Municipal de Saúde de Gurupi TO, foram notificados 11 casos de sífilis congênita $(p=0,8660) ; 148$ casos de HIV/Aids $(p=0,0034) ; 131$ casos de Condiloma $(p<0,0001)$; 96 casos de Hepatites Virais $(p<0,0001)$ e 50 casos de Síndrome do Corrimento Uretral no Homem $(p=0,8442)$. Conclusão: Com essa pesquisa concluiu-se que as IST mais notificadas e com um aumento gradativo durante os anos pesquisados foram os casos de HIV/Aids, seguido por Condiloma e Hepatites Virais.

Palavras-chave: Doenças Sexualmente Transmissíveis. Enfermagem. Epidemiologia.
Docente da Universidade de Gurupi.

E-mail:

claudianeri.enfa@gmail.com

${ }_{2}$ Graduada em Enfermagem pela Universidade de Gurupi.

${ }_{3}$ Graduada em Enfermagem pela Universidade de Gurupi.

Pós-Doutor FZEA/USP Pirassununga.

Mestre e docente Universidade de Gurupi.

\section{ABSTRACT}

Introduction: Sexually Transmitted Infections (STIs) affect a large part of the population, and some of these STIs are compulsory to report, which contributes to the control and reduction of these rates. Objective: The aim of this study was to evaluate the incidence of STI cases in individuals from Gurupi - TO between the years 2013 to 2017. Material and methods: Data collection was performed in the Epidemiological Surveillance database of the Municipal Health Department The incidence between the years was compared using the Chi-square test, at a significance level of $5 \%$, with the aid of the "chisq.test" package of the R Development Core Team software, then elaborating explanatory graphics. Results: In the evaluation of the historical series, it was found that between the years 2013 to 2017, according to the Municipal Health Department of Gurupi - TO, 11 cases of congenital syphilis were reported ( $p=0.8660)$; 148 cases of HIV / AIDS ( $p=0.0034) ; 131$ cases of Condyloma ( $p<0.0001) ; 96$ cases of viral hepatitis $(p<0.0001)$ and 50 cases of urethral discharge syndrome in men $(p=$ 0.8442 ). Conclusion: With this research it was concluded that the most reported STIs and with a gradual increase during the years surveyed were the cases of HIV / AIDS, followed by Condyloma and Viral Hepatitis.

Keywords: Epidemiology. Nursing. Sexually Transmitted Diseases. 


\section{INTRODUÇAO}

Segundo a nova atualização da estrutura regimental do Ministério da Saúde, por meio do Decreto n 8.901/2016 publicada no Diário Oficial da União em 11.11.2016, Seção I, páginas 03 a 17, a nomenclatura DST que corresponde a Doenças Sexualmente Transmissíveis, será substituída por IST (Infecções Sexualmente Transmissíveis); 0 Departamento de Vigilância, Prevenção e Controle das IST, do Vírus da Imunodeficiência Humana (HIV)/Aids e das Hepatites Virais passam a usar a nova atualização por ser uma denominação oficial. (BRASIL, 2017).

A denominação 'D', de 'DST', vem de doença, que remete a sinais e sintomas visíveis no organismo da pessoa infectada. Já 'Infecções' pode apresentar períodos assintomáticos, como por exemplo, a sífilis, herpes genital e condiloma acuminado; ou, se manter assintomática por toda a vida, como acontece muitas vezes com o Papiloma Vírus Humano (HPV) e o vírus da Herpes. (BRASIL, 2017).

As Infecções Sexualmente Transmissíveis são consideradas um problema mundial devido seus agravos no organismo do indivíduo acometido. Essas Infecções são causadas por mais de 30 agentes etiológicos que podem ser vírus, bactérias, fungos e protozoários; que são transmitidas por via oral, anal ou vaginal sem o uso de preservativos; por via sanguínea, como por exemplo, o uso compartilhado de seringas ou instrumentos perfuro cortantes e de mãe para filho durante a gestação, o parto ou a amamentação. (BRASIL, 2015).

O grupo de IST é composto por: HIV/Aids, Cancro mole (cancroide), Condiloma acuminado (Papiloma Vírus Humano - HPV), Doença Inflamatória Pélvica (DIP), Donovanose, Gonorreia e infecção por Clamídia, Hepatites virais, Herpes genital, Infecção pelo HTLV, Linfogranuloma venéreo (LGV), Sífilis e Tricomoníase. (BRASIL, 2017).

No Tocantins, em 1999, foram notificados 155 casos de hepatites virais. Em 2000 passou-se a registrar separadamente os tipos de hepatite como A, B, C e D. Em 2003 foram notificados 107 casos de hepatite B e 27 de hepatite C. Sua distribuição geográfica é heterogênea com prevalência mais elevada na região norte do país. De 1988, que foi o início da epidemia, até julho de 2003, foram notificados 375 casos de AIDS no Estado. A AIDS está presente em todas as regiões do Estado, com maior prevalência na região de Palmas (40\%), seguido de Araguaína (32\%) e Gurupi (13,6\%). (BRASIL, 2007).

O tratamento das IST melhora a qualidade de vida do indivíduo de forma que venha a interromper a passagem dessas infecções. Este deve ser realizado também nos parceiros 
sexuais em busca de uma melhor eficácia. $O$ atendimento e tratamento das IST são gratuitos conforme disponibilizado pelo Serviço Único de Saúde - SUS. (BRASIL, 2016).

Os preservativos e os anticoncepcionais são métodos de grande importância contra uma gravidez indesejada, porém, a camisinha, tanto a masculina quanto a feminina, não são apenas métodos contraceptivos, mas sim, meios extremamente importantes para a prevenção de uma contaminação por algum tipo de IST. (BRASIL, 2015).

Devido o termo IST ser sobrecarregado de dúvidas e as infecções serem um problema que envolve a população no geral, esta pesquisa teve como objetivo esclarecer aspectos de cada infecção e suas peculiaridades e, principalmente, levantar dados no município de Gurupi - TO, por meio do banco de dados de notificações de Infecções Sexualmente Transmissíveis, notificados no Departamento de Vigilância Epidemiológica da Secretaria Municipal de Saúde do Município de Gurupi - TO.

\section{MATERIAIS E METODOS}

Trata-se de uma pesquisa aplicada, de caráter exploratório, descritivo e explicativo com ênfase em levantamentos de dados de forma documental. A amostra foi composta por todos os casos notificados por meio do banco de dados de notificações de Infecções Sexualmente Transmissíveis, informados no Departamento de Vigilância Epidemiológica da Secretaria Municipal de Saúde do Município de Gurupi no estado do Tocantins no período de 2013 a 2017. Foram excluídos da pesquisa casos não notificados, endereço, sexo, data de nascimento e número de notificação.

Os dados foram obtidos por meio de análise do banco de notificações de Infecções Sexualmente Transmissíveis, eleita como técnica de coleta de dados. A pesquisa foi realizada com observação das variáveis: IST notificada e ano de notificação (2013 a 2017).

Os resultados foram apresentados por meio de média e mediana e desvio padrão. A incidência entre os anos foi comparada por meio do teste Qui-quadrado, ao nível de significância de $5 \%$, com o auxílio do pacote "chisq.test" do software R Development Core Team, elaborando então gráficos explicativos onde os critérios foram IST e ano de notificação.

Esta pesquisa foi desenvolvida conforme diretrizes preconizadas na resolução CNS 466/12. Vale ressaltar que a pesquisa não teve a necessidade de conter um TCLE (Termo De Consentimento Livre Esclarecido), pois a coleta de informações foi feita em um banco de dados da secretaria de vigilância epidemiológica, que não disponibiliza informações que exponham a identidade do indivíduo portador de IST, além disso, não se teve acesso direto 
com o indivíduo (a pesquisa foi com banco de dados), e dessa forma o TCLE é dispensado. Foi aprovado pelo comitê de Ética e Pesquisa da Universidade de Gurupi (Parecer $n^{\circ}$ 2.240.787)

\section{RESULTADOS E DISCUSSÁO}

$\mathrm{Na}$ avaliação da série histórica, verificou-se que entre os anos de 2013 a 2017, segundo a Secretaria Municipal de Saúde de Gurupi - TO, foram notificados 11 casos de sífilis congênita; 148 casos de HIV/Aids; 131 casos de Condiloma; 96 casos de Hepatites Virais e 50 casos de Síndrome do Corrimento Uretral no Homem.

Verificou-se que os casos de Sífilis Congênita ( $p=0,8660)$ (GRÁFICO 1) e de Corrimento Uretral em Homens ( $p=0,8442)$ (GRÁFICO 2) não obtiveram um crescimento entre os anos avaliados. Aparentemente percebemos a diferença de algumas unidades nos casos notificados, mas essa diferença é mínima para ser considerada importante; isso quer dizer que entre os anos de 2013 a 2017 elas se se mantém estabilizadas.

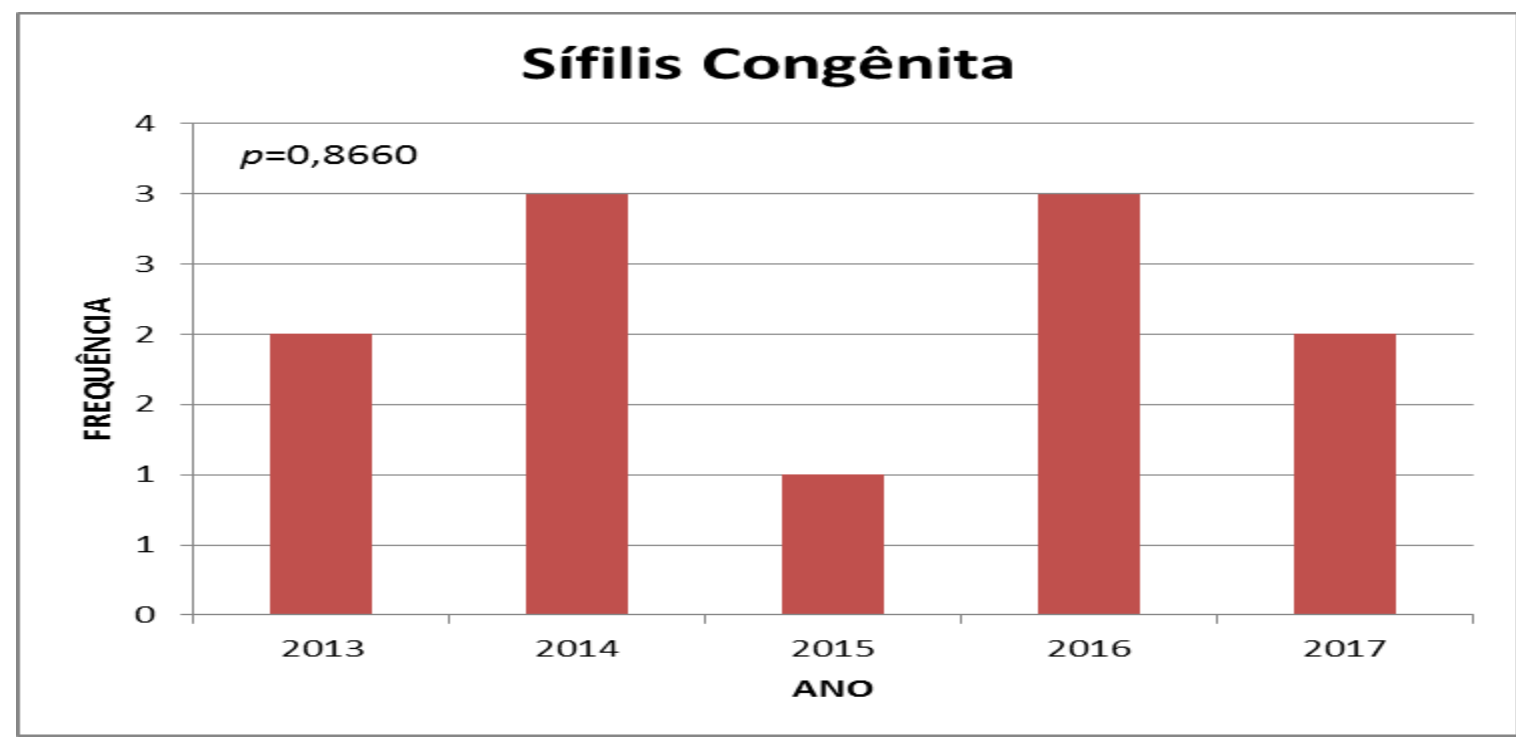

Gráfico 1 - Incidência de Casos de Sífilis Congênita entre os anos de 2013 a 2017 Disponibilizado pela SEMUS 


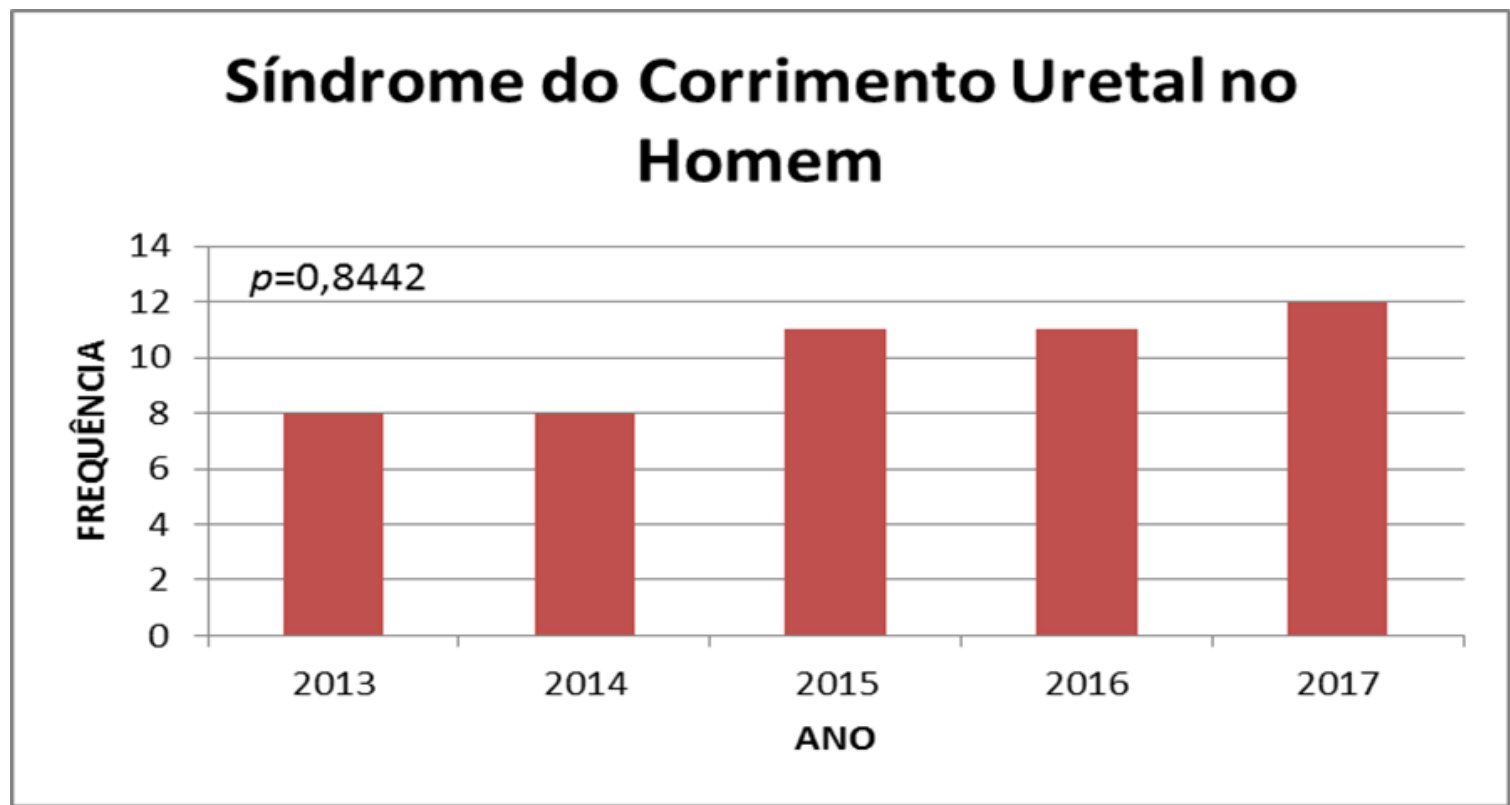

Gráfico 2 - Incidência de Casos da Síndrome do Corrimento Uretral no Homem entre os anos de 2013 a 2017 Disponibilizado pela SEMUS.

Em contrapartida, houve diferença estatisticamente significativa para os casos notificados de HIV/Aids ( $p=0,0034)$ (GRÁFICO 3), Condiloma $(p<0,0001)$ (GRÁFICO 4) e Hepatites Virais ( $p<0,0001$ ) (GRÁFICO 5) entre os anos de 2013 a 2017.

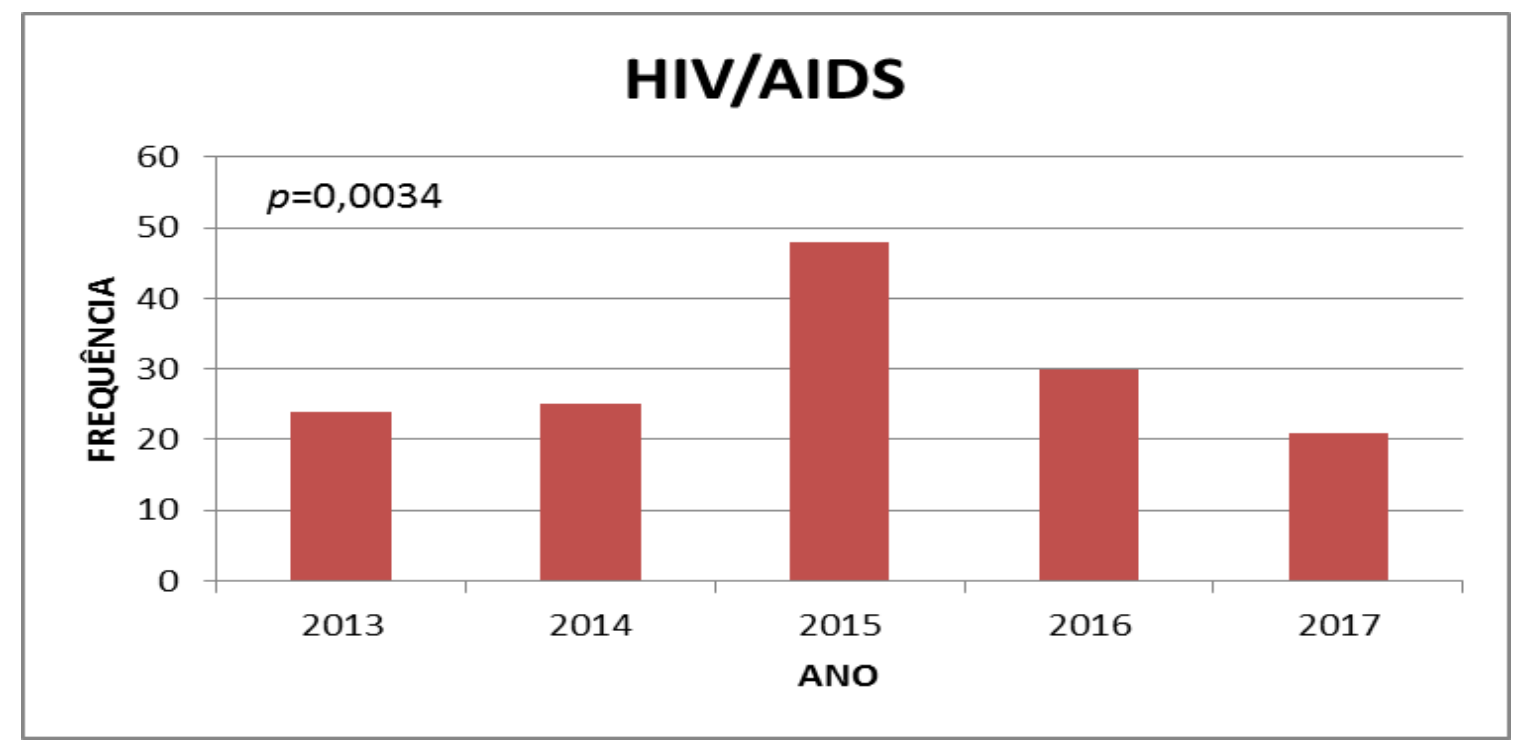

Gráfico 3 - Incidência de Casos de HIV/Aids entre os anos de 2013 a 2017 Disponibilizado pela SEMUS. 


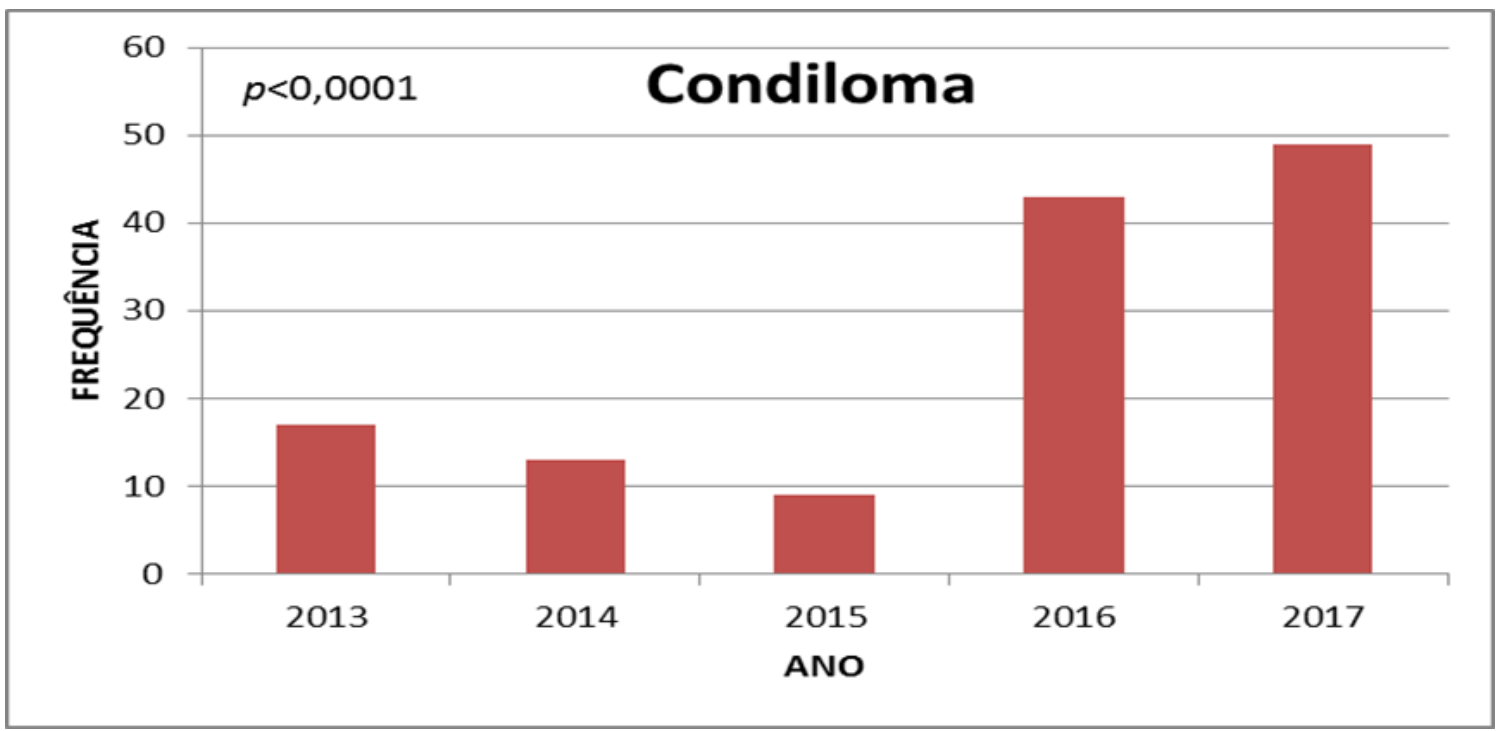

Gráfico 4 - Incidência de Casos de Condiloma entre os anos de 2013 a 2017 Disponibilizado pela SEMUS.

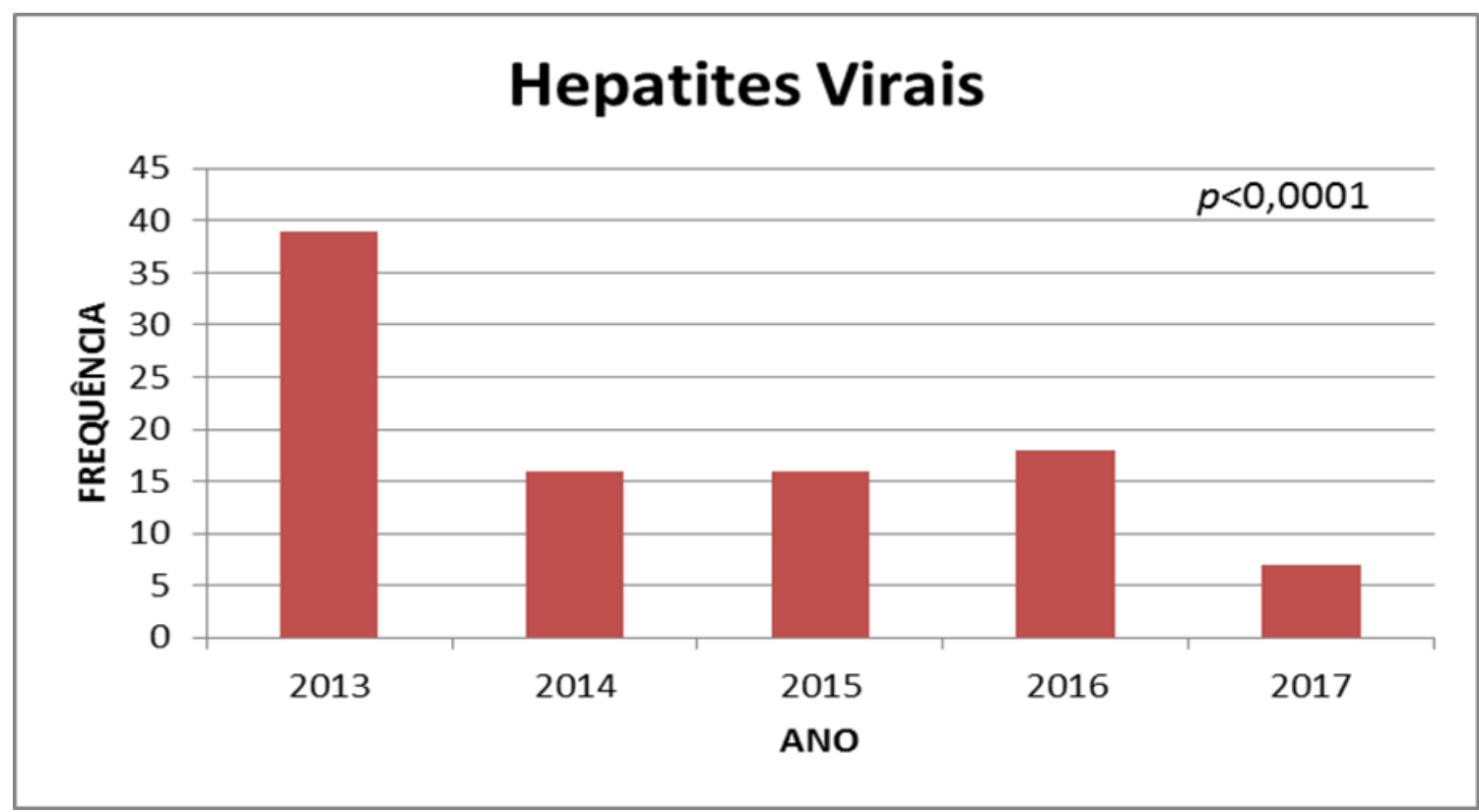

Gráfico 5 - Incidência de Casos de Hepatites Virais entre os anos de 2013 a 2017 Disponibilizado pela SEMUS.

Segundo o Boletim Epidemiológico de Sífilis (2016), foram notificados no Sistema de Informação de Agravos de Notificação (SINAN) de 1998 a junho de 2016: 142.961 casos de Sífilis Congênita, sendo, 11.846 (8,3\%) no Norte, 64.398 (45,0\%) na região Sudeste, $44.054(30,8 \%)$ no Nordeste, 14.300 (10,0\%) no Sul, e 8.363 (5,8\%) no Centro-Oeste. A média nacional estipulada sobre a Sífilis Congênita (6,5 casos/mil nascidos vivos) encontrase superior nos estados: Tocantins (9,1 casos/mil nascidos vivos); Rio de Janeiro (12,4 casos/mil nascidos vivos); Rio Grande do Sul (11,5 casos/mil nascidos vivos); Sergipe (10,9 
casos/mil nascidos vivos), Espirito Santo (9,1 casos/mil nascidos vivos); Rio Grande do Norte (9,0 casos/mil nascidos vivos); Ceará (8,7casos/mil nascidos vivos); Pernambuco (8,5 casos/mil nascidos vivos); Piauí (7,8 casos/mil nascidos vivos); Alagoas (7,4 casos/mil nascidos vivos) e Mato Grosso do Sul (7,2 casos/mil nascidos vivos).

Segundo a Organização Mundial de Saúde (OMS), no Brasil, os casos de infecções por Gonorreia e HPV na população sexualmente ativa são de 1.541 .800 e 685.400 respectivamente. (BRASIL, 2017).

No SINAN, de 1999 a 2016, foram notificados 561.058 casos confirmados de hepatites virais no Brasil, sendo: 162.847 (29,0\%) referentes aos casos de hepatite A, 212.031 (37,8\%) de hepatite B, 182.389 (32,5\%) de hepatite C e 3.791 (0,7\%) de hepatite D (BRASIL, 2017).

Entre os anos de 2007 a 2016 foram notificados, também no SINAN, 136.945 casos de infecção de HIV no Brasil, sendo: 6.868 na Região Norte (6,3\%); 71.396 no Sudeste $(52,1 \%) ; 28.879$ no Sul $(21,1 \%) ; 18.840$ no Nordeste (13,8\%); 9.152 no Centro-Oeste (6,7\%) (BRASIL, 2016).

Nesse estudo, identificou-se que algumas IST tiveram seus índices elevados e/ou oscilaram durante os anos avaliados, já outras, obtiveram apenas uma pequena diminuição; informações estas confrontadas apenas com os anos em que obtivemos acesso, 2013 a 2017. Diante deste fato, questiona-se a necessidade de uma melhoria nas políticas públicas com a finalidade de facilitar o atendimento aos usuários deste tipo de cuidados.

O papel da enfermagem diante das IST é promover ações educativas por meio do desenvolvimento de atividades, promoção e prevenção destas; atuando também de forma individual, dentro das famílias e na comunidade. O enfermeiro também contribui para o diagnóstico precoce e para a adesão do tratamento, tratamento este que deve ser realizado juntamente com o parceiro sexual. Além do mais, é de suma importância o enfermeiro acolher o paciente, prestar cuidados e/ou coordenar e administrar os setores que iram prestar a assistência. O paciente ao procurar cuidados, deve ser atendido por uma equipe multidisciplinar e recepcionado pela equipe de enfermagem, pelo qual terá um vínculo contínuo. Para um melhor atendimento, a equipe multidisciplinar não pode ter nenhum tipo de preconceito diante da IST que o paciente possui, e também, esses profissionais devem estar constantemente atualizados em relação a essas infecções. (REIS; GIR, 2002).

Em face ao exposto, o estudo trouxe uma ampliação de conhecimento para os profissionais da saúde, acadêmicos e sociedade. 


\section{CONSIDERAÇOES FINAIS}

As IST ainda são consideradas um importante problema de saúde pública; e mesmo essas infecções sendo evitáveis, ainda possuem índices elevados e muitas vezes não são detectadas precocemente, o que aponta um cenário propício para o surgimento de complicações graves advindas de algumas dessas IST.

Com essa pesquisa concluiu-se que as IST mais notificadas e com um aumento gradativo durante os anos pesquisados foram os casos de HIV/Aids, seguido por Condiloma e Hepatites Virais. Durante o período analisado não houve aumento significativo no número de notificações de Sífilis Congênita e Corrimento Uretral no Homem

A diminuição da incidência de novos casos de IST pode ocorrer devido à melhoria de políticas públicas por meio da distribuição de verbas advindas de parcerias do Governo Estadual com seus municípios, por meio de projetos Federais do Ministério da saúde com enfoque na temática, projetos cujo objetivo é atualização das equipes de saúde, reflexão sobre o tema e treinamento das equipes para que se prestem um atendimento humanizado independente da patologia ou infecção que o indivíduo possua. Após a implementação das políticas poderemos obter resultados significativos na incidência.

Ações de prevenção devem ser desenvolvidas, para gerar uma conscientização da sociedade perante o uso de preservativos, considerado o método mais eficaz contra a transmissão de IST. Devendo os serviços de saúde, escolas e comunidade se unirem, visando transformar o conhecimento sobre IST em uma prática sexual segura e responsável.

Com isso, torna-se relevante o desenvolvimento de novos estudos sobre as outras infecções no município de Gurupi - TO, com intuito de analisar e avaliar a verdadeira situação dos índices epidemiológicos frente as demais Infecções Sexualmente Transmissíveis.

\section{REFERÉNCIAS}

BRASIL. Departamento de IST, Aids e Hepatites Virais. DST no Brasil. Disponível em: $<$ http://www.aids.gov.br/pagina/dst-no-brasil>. Acesso em 19 fev. 2017.

BRASIL. Departamento de IST, Aids e Hepatites Virais. Departamento passa a utilizar nomenclatura "IST" no lugar de "DST". Disponível em:

$<$ http://www.aids.gov.br/noticia/2016/departamento-passa-utilizar-nomenclatura-ist-nolugar-de-dst>. Acesso em: 19 fev. 2017.

BRASIL. Ministério da Saúde, Secretaria de Vigilância em Saúde, Departamento de DST, 
Aids e Hepatites Virais. Protocolo Clínico e Diretrizes Terapêuticas para Atenção Integral ás Pessoas com Infecções Sexualmente Transmissíveis. Brasília, 2015. 17 p. Disponível em:<http://www.fmt.am.gov.br/layout2011/cedstaids/PCDT\%20IST\%202015.PDF>. Acesso em: 19 fev. 2017.

BRASIL. Departamento de IST, Aids e Hepatites Virais. Quais são as DST, Doenças sexualmente transmissíveis. Disponível em: $<$ http://www.aids.gov.br/pagina/quais-saodst>. Acesso em 19 fev. 2017.

BRASIL. Sistema nacional de vigilância em saúde. Relatório de situação. TOCANTINS. Brasília, DF, 2007. p. 10 e 13. Disponível em: <http://bvsms.saude.gov.br/bvs/publicacoes/to1.pdf>. Acesso em: 12 abr. 2017.

BRASIL. Departamento de IST, Aids e Hepatites Virais. DST no Brasil. Disponível em: <http://www.aids.gov.br/pagina/dst-no-brasil>. Acesso em 19 fev. 2017.

BRASIL. Departamento de IST, Aids e Hepatites Virais. O que são as IST. Disponível em: $<$ http://www.aids.gov.br/pagina/o-que-sao-dst>. Acesso em 21 fev. 2017.

BRASIL. Boletim Epidemiológico Sífilis 2016. Secretaria de Vigilância em Saúde, Ministério da Saúde. Brasília, DF, 2016. P. 7 e 8. Disponível em: $<$ file:///C:/Users/Usuario/Downloads/2016 030 sifilis publicao2 pdf 51905\%20(2).pdf>. Acesso em 06 nov. 2017.

BRASIL. Boletim Epidemiológico Hepatites Virais 2017. Secretaria de Vigilância em Saúde, Ministério da Saúde. Brasília, DF, 2017. P. 5. Disponível em: <file:///C:/Users/Usuario/Downloads/boletim hepatites virais2017 pdf 25238\%20(2).pdf>. Acesso em 06 nov. 2017.

BRASIL. Boletim Epidemiológico HIV/Aids 2017. Secretaria de Vigilância em Saúde, Ministério da Saúde. Brasília, DF, 2017. P. 2. Disponível em: <file:///C:/Users/Usuario/Downloads/boletim 20161 pdf 16375\%20(1).pdf>. Acesso em 06 nov. 2017.

CONITEC, Comissão Nacional de Incorporação de Tecnologia no SUS. Protocolo Clínico e Diretrizes Terapêuticas, Infecções Sexualmente Transmissíveis. Protocolo, Relatório de Recomendação. Departamento de IST, Aids e Hepatites Virais, Secretaria de Vigilância em Saúde, Ministério da Saúde. PROTOCOLO CLínICO E DITETRIZES TERAPÊUTICAS (PCDT): ATENÇÃO INTEGRAL ÁS PESSOAS COM INFECÇÕES SEXUALMENTE TRANSMISSÍVÉIS. Brasília, 2015. 2 p. Disponível em: $<$ http://conitec.gov.br/images/Consultas/Relatorios/2015/Relatorio PCDT IST CP.pdf>. Acesso em: $21 \mathrm{fev} .2017$.

REIS, Renata Karina; GIR, Elucidar. CARACTERIZAÇÃO DA PRODUÇÃO CIENTÍFICA SOBRE DOENÇAS SEXUALMENTE TRANSMISSIIVEIS E HIV/AIDS PUBLICADOS EM PERIÓDICOS DE ENFERMAGEM DO BRASIL. Revista Esc. Enfermagem, São Paulo, v. 4, n. 36, p. 377, 2002. 